\title{
A Call for Lecturers to Move Away from Traditional Teaching to Facilitation in the Institutions of Higher Education: Challenges Encountered by Lecturers in the First Year Classes of a Rural University of the Eastern Cape
}

\author{
Mr Malatji K.S
}

University of Fort Hare (KMalatj@ufh.ac.za)

\author{
Doi:10.5901/mjss.2014.v5n11p123
}

\begin{abstract}
This paper investigated the challenges experienced by lecturers during facilitation of learning in the first year classes at an institution of higher learning in South Africa in the Eastern Cape Province. The aim of the study was to investigate the challenges experienced by facilitators during facilitation of first year classes, with the aim of recommending the best ways of managing such facilitation. The researcher used qualitative research approach in this study with case study research design. Population consisted of lecturers from 2 faculties and focus-group interviews were used to collect data from 15 participants that has less than 5 years working as lecturers. With regard to data analysis, themes were identified and analysed in a qualitative approach. The results of this study revealed that students are unable to cope with facilitation since they are used to traditional teaching approach from their high schools. The study concludes that due to students failing to cope with facilitation, this result into high dropout of first year students. The study therefore, recommends that lecturers should connect teaching and facilitation by gradually introducing and preparing students to move away from traditional learning to facilitation, using small group teaching. The study further recommends intensive use of facilitation rather than teaching, because facilitation prepare students to be critical thinkers and responsible for their learning. Kolb's model of learning style was also recommended in the concerned rural university so that lecturers may understand how students learn.
\end{abstract}

Keywords: traditional teaching, facilitation, lecturers, group teaching, cooperative learning, whole class discussion.

\section{Background and Introduction of the Study}

Teaching is a process of imparting knowledge and skills from lecturer to students (Craig and Zimring, 2000). One of the disadvantages of traditional teaching students becomes recipients of information, without active participation. Teaching can be regarded as a process whereby a lecturer leads a group of students in acquiring new skills, knowledge, or understanding. While in facilitation a lecturer is helping/making it easy for students to learn together in a group, or to achieve something together as a group. One of the advantages of facilitation is that facilitators assist students to learn through discussing a problem by giving advice rather than telling them what to do (Ericksson, Krampe and Tesch-Romer, 2000)). Lecturer assists the group as they work towards achieving a common goal and students become responsible for their own learning.

According to Schank (1999) facilitation offers everyone in the group the chance to express their ideas and to feel as if they are part of a team. Since the group arrives at a mutual conclusion, it's easier for individual members to carry out the group's goals and to feel less inclined to work on individual agendas. A facilitator helps individuals build on their skills and learn new ones. Facilitation serves as a positive way to resolve conflicts and clarify misunderstandings among a diverse group of individuals. Lecturers often act as facilitators, and facilitators sometimes teach. In order for either to be successful, lecturers must be active listeners. Facilitators in particular make use of this skill. They listen to an entire statement made by a group member before responding. They try to understand the group member's point of view in a non-judgmental way. Active listeners often ask questions of the group to clarify what group members are saying. Active listeners are slow to jump to conclusions and keep the group focused on the subject of discussion (Hmeo, Helton and Kolodner, 2000).

Facilitators complete a rigorous qualification and are continuously engaged in activities that enhance their effectiveness at facilitating learning. This includes a rich repertoire of openers, closers, energizers, and interactive lecture techniques. Facilitators begin as highly qualified content instructors. They then work to build their facilitation skills through development activities. So even though we call them facilitators, they are really both and can apply either style based on participants' needs and the course learning objectives (Holbrook and Kolodner, 2000).

Jansson, (1993: 33) presented eight competencies that facilitators are expected to have: Prepares for training 
delivery; creates a positive learning climate; establishes credibility as facilitator; adapts teaching to what participants know and how they learn; focus on learning objectives; facilitates learning by encouraging participation; employs a variety of teaching tools and techniques; and ensures learning outcomes.

An effective class depends on the quality of the facilitator. A well designed course alone does not make an effective class. A weak facilitator who is dependent on slides and lecture will deliver a weak class, regardless of the quality of the course design and materials. A strong facilitator with a deep knowledge of the content, an understanding of how student learn, and a rich repertoire of activities to facilitate learning can deliver an effective class despite weak course design and materials. Students participate in formal learning activities to enhance their ability to produce specific results. Producing results through learning is best achieved in an environment in which a clear, active, measurable objective (result) is identified and an effective facilitator guides the process (Kolodner, 1997).

The use of teaching with the Constructivist Learning Theory can used to strengthen the use of facilitation in the institution of higher learning's classroom. The theory is relevant for facilitation because it encourages critical thinking and encourages students to ask follow-up questions during discussions. Some lecturers make use of a direct style of teaching by, for example, telling and showing students directly. Such lecturers use objects during teaching and students gain insight through observation (Jacobs, Vakalisa \& Gawe, 2004). While on the other hand some lecturers prefer an indirect style of teaching because they want to encourage students to find out and think for themselves. According to Jacobs (2004), et al lecturers using an indirect style of teaching seem to be effective because they can select and use some strategies that are most appropriate under circumstances. Within indirect teaching, lecturers may use different facilitation strategies that include small group teaching, co-operative learning, social constructivism and also learning theories that are relevant to facilitation of teaching and learning.

However, working with first year student can be a challenge since they are still used to teaching approach that is pre-dominant in high schools. The new environment can also be a challenge for students, especially first-year group. Another challenge may be that the University that the study was conducted in was in rural area, as a results majority of students were from rural area. Some of the challenges associated with students from rural areas are poor communication skills (since most of them English is their second language); lack of self-confidence among others. Therefore, the study sought to answer the question what are the challenges experienced by lecturers when managing facilitation in the rural university.

\section{Theoretical Framework}

With regard to theoretical framework, Kolb, (2006) model of learning style was used. The theory is relevant to this study because it explain in detail learning styles that students undergo. Kolb's different learning style can be used to assist first students to learn though facilitation, and lecturers can also refer to this theory to understand how students learn. Kolb explains that different people naturally prefer a certain single different learning style. Various factors influence a person's preferred style: notably in his experiential learning theory model (ELT) Kolb defined three stages of a person's development, and suggests that our propensity to reconcile and successfully integrate the four different learning styles improves as we mature through our development stages.

\section{Brief descriptions of the four Kolb learning styles in the context of higher education:}

\subsection{Diverging (feeling and watching - CE/RO)}

These students are able to look at things from different perspectives. They are sensitive. They prefer to watch rather than do, tending to gather information and use imagination to solve problems. They are best at viewing concrete situations several different viewpoints. Kolb called this style 'Diverging' because these students perform better in situations that require ideas-generation, for example, brainstorming. Students with a Diverging learning style have broad cultural interests and like to gather information and they prefer to work in groups, to listen with an open mind and to receive personal feedback (Kolb, 2006).

\subsection{Assimilating (watching and thinking - AC/RO)}

The Assimilating learning preference is for a concise, logical approach. Ideas and concepts are more important than people. These students require good clear explanation rather than practical opportunity. They excel at understanding wide-ranging information and organising it a clear logical format. Students with an Assimilating learning style are less 
focused on people and more interested in ideas and abstract concepts and they are more attracted to logically sound theories than approaches based on practical value. This learning style is important for effectiveness in information and science careers. In formal learning situations, students with this style prefer readings, lectures, exploring analytical models, and having time to think things through. (Kolb, 2006).

\subsection{Converging (doing and thinking - $A C / A E)$}

According to Kolb, (2006) students with a Converging learning style can solve problems and will use their learning to find solutions to practical issues. They prefer technical tasks, and are less concerned with people and interpersonal aspects. Students with a Converging learning style are best at finding practical uses for ideas and theories. They can solve problems and make decisions by finding solutions to questions and problems. Moreover, students with a Converging learning style are more attracted to technical tasks and problems than social or interpersonal issues. A Converging learning style enables specialist and technology abilities. Lastly, students with a Converging style like to experiment with new ideas, to simulate, and to work with practical applications.

\subsection{Accommodating (doing and feeling - CE/AE)}

The Accommodating learning style is 'hands-on', and relies on intuition rather than logic. These students use other people's analysis, and prefer to take a practical, experiential approach. They are attracted to new challenges and experiences, and to carrying out plans. They commonly act on 'gut' instinct rather than logical analysis. Students with an Accommodating learning style will tend to rely on others for information than carry out their own analysis. This learning style is prevalent and useful in roles requiring action and initiative. Students with an Accommodating learning style prefer to work in teams to complete tasks. They set targets and actively work in the field trying different ways to achieve an objective (Kolb, 2006).

\section{Statement of the Problem}

Facilitation offers everyone in the group the chance to express their ideas and to feel as if they are part of a class. However, moving from teaching to facilitation in the university under study can be a challenge since first year students are still comfortable with traditional teaching that was used in schools. As a result, lecturers experience a challenge when facilitating students in the first years, and these may results into many students not coping with the system and end up dropping out.

\section{Research Questions}

- What are the challenges facing lecturers when using facilitation in their lectures in the first year classes?

- How do lecturers assist students to cope with facilitation as a learning strategy?

- What model can be suggested for lecturers to use during facilitation of students' learning?

\section{Research Methodology}

\section{Research Paradigm}

The paradigm used in this study was the qualitative approach. The purpose of qualitative research is to develop an understanding of individuals and events in their natural state, taking into account the relevant context (Leedy, 2001:91). Qualitative research is predicted on the assumption that each individual, each culture and each setting is unique. In qualitative research, interpretation of data was done by identifying themes and generates discussion (Kolb, 1999:3). Procedures are not strictly formalized, scope is more likely to be undefined, and a more philosophical mode is adopted (Mouton \& Marias, 1998:166). Therefore this study was epitomized as qualitative research. It can be epitomized as qualitative because:

- The study was conducted in a natural setting in which the lecturers were asked questions to answer based on facilitation of learning. Focus-group interviews were used because the researcher wanted to gather in-depth information about lecturers' views; challenges and how they manage facilitation during their lecturers. 
- An important concern of qualitative researchers is the meaning of human behaviour and experience. In this study the researcher was interested in the facilitation of learning by lecturers,

- The data collected emanated from focus-group interviews; and did not follow numerical or statistical procedures. Thus the focus of this proposed study was on understanding and meaning through verbal narratives rather than through numbers,

- The data was gathered and analysed by qualitative methods; small groups are normally investigated in qualitative research (Van Der Westhuizen, 1999:127). In the context of study the participants consisted of lecturers in two faculties, and this was considered as a small group.

\section{Research Design}

The research design used in this study was phenomenological research design. Phenomenological research design is the kind of research whereby the researcher forms part of the day to day life of his/her population, while gathering data (Criticos 2002:44). In this study, the researcher is working in the institution; therefore it gave him opportunity to spend few days getting to know the staff of the relevant faculties and how they manage facilitation in order to gather information. The reason for choice of a phenomenological research design is that it enables the researcher to be in a particular faculty, for a particular period in order to find out how lecturers manage facilitation. The researcher formed part of the staff, and engage on daily activities of lecturers in these faculties. These enabled lecturers or members of staff to behave in a normal behaviour without being aware that the researcher is collecting some sort of information about their management of facilitation. The most important thing in this stage was for lecturers not to be biased when providing with information; because sometimes when participants are aware that you are collecting information; they might provide information just to please you as a researcher, but if they are not aware that you are collecting information they will not be biased.

\section{Population and Sampling}

The population comprised lecturers from two faculties at an institution of higher learning. The total population of these faculties was thirty eight. Du Plooy (1997:48) refers to sampling as the rigorous procedures involved when selecting individuals from a large population. A sample is therefore a group of subjects chosen from the population using a particular sampling method. During data collection focused group interviews was used. During focused group fifteen lecturers from two faculties that are teaching first year class volunteered to participate on this study. Each session of focus-group consisted of five lecturers with less than five years teaching experience, and the total of three focus-group sessions.

\section{Data Collection and Instruments}

To carry out any type of research investigation, data must be gathered. Many different methods and procedures have been developed to aid in the acquisition of data. These procedures employ distinctive ways of collecting the data. Each is particularly appropriate for certain sources of data, yielding information of the kind and in the form that can be most effective (Kothari, 1997: 207). Considering the fact that the study followed qualitative approach, focus-group interviews were used to gather in-depth information about the use facilitation in institution of higher learning.

\section{Trustworthiness}

Trustworthiness is a set of quality criteria for judging interpretive research, which is also known as 'authenticity criteria' (Kolb, 1999:36). In this regard, qualitative research theorists advise researchers to explain what precautions they have taken to enhance the trustworthiness of the findings of their studies. Therefore, the researcher gave an overview of two trustworthiness criteria: credibility and transferability.

\subsection{Credibility}

The researcher is working in the University; as a result he is familiar with the culture of this University. To ensure credibility of the results the researcher has done some consultations about facilitation related activities before the actual data collection sessions. To ensure honesty and guanine information, participants was given a chance to refuse to participate in the study, in other words the participation was based voluntary. 


\subsection{Transferability}

All Universities in South Africa are expected to keep certain national and international standard. The transferability of credits across the Universities unified the curriculum and practice of teaching in higher institution. Therefore, the results of this can be transferred or applied in other universities, be it nationally or internationally.

\section{Data Analysis}

Davison (1997) states that data analysis is the process of making sense out of data, which involves consolidating, reducing and interpreting what has been said and what the researcher has seen and read. It is thus the process of understanding, making sense and meaning of the data. This understanding was organised into a descriptive account. Data collected from taped recorded interviews were transcribed verbatim. After transcribing interviews, a sense of the whole was obtained by reading carefully with understanding and summarizing the salient aspects.

\section{Ethical Issues}

This concerns the importance of both accurately informing the respondents as to the nature of research and obtaining their written consent to participate (Babbie 2007:64). Coercion is not to be used to force participation and the respondents may terminate their involvement in the research at any time. Participation of the respondents was voluntary. The researcher assured the respondents that the information they provided was only for research purposes. Furthermore, their names were not to be disclosed and the interviews were conducted in a private place with only the respondent and researcher present. Lastly, the researcher shown respect for the well-being of the participants and the right to selfdetermination.

According to Kolb (1999:33), the validity of the instrument produces accurate results or information. In supporting Kolb's idea the researcher ensured validity of the instruments to collect data. The researcher first piloted the instruments, which according to Taylor (2008:34), is to test if the instrument will address the problem. Lastly, the researcher got certificate of ethical clearance from the University before conducting the study in the institution.

\section{Results or Findings}

\section{Results/Findings and Discussion of Findings}

When lecturers were asked how they use facilitation as a teaching strategy, the following themes were identified:

- The use of group teaching;

- The use of co-operative teaching;

- The use of whole class discussion method;

- The use of blackboard: discussion tool.

The use of group teaching is recommended by the new education system in South Africa because it allows students to talk for longer lengths of time than in whole class situation, and this encourage less confident students to contribute their ideas. Secondly, it allows lecturers to individualise their tuition more than in whole class situation (Critocos, 2005). By grouping weaker students in one or two groups, lecturers are able to work closely on their learning difficulties without holding up stronger students. According to Critocos (2005) these students will be set more advanced work with which they can continue while the lecturer deals with students having a problem.

Thirdly, grouping also provides opportunity for lecturers to use students as lecturers. Stronger students can be used to facilitate learning in groups and possibly clarify issues that a lecturer hasn't been able to do. Fourth, well managed group according to Critocos (2005) creates a learning culture which teaches students how to listen to others, share ideas, and model other students' ways of thinking and doing things. Group work that requires hands no activities provide opportunity for active learning. In addition, the process of group work will develop many of the skills that future citizen need. For example students who learn in groups frequently and over a long period develop strong inter-personal skills; they develop strong co-operative and collaborative working skills; and they also develop strong problem solving and critical thinking skills.

Besides group teaching, lecturers mentioned that the use of cooperative learning can also assist them to move students from traditional teaching/learning to facilitation. Cooperative learning involves students working together and 
being responsible for both their own learning and each other's learning (Leedy, 2001). Cooperative learning is different from group work because lecturer sets rules for student and teaches the skills of cooperative learning. This is a powerful tool for facilitation because during facilitation the role of a lecturer is also to guide student not to lead them. Moreover, cooperative learning involves student to student interaction in the process of fostering successful learning by all. Students are given the opportunity to react on ideas, experience, insight and knowledge of generating alternative ways of thinking and feeling. As learning occurs in the social context of lecture hall, knowledge is co-constructed through interaction with other and this is what facilitation encourages to students. According to Jacobs et al (2004) co-operative learning is a way of teaching in which students work together to ensure that all members in their groups have learnt and understood the same content. Such co-operation gives students the emotional and academic support that helps them to persevere against the many obstacles they face at University.

Whole class discussion method is another tool that can result in to successful facilitation. During whole discussion, students are guided by the lecturer by providing them with the right questions to discuss. According to Jacobs et al (2004) whole class discussion method demands that the class be designed and managed in a manner that encourages students to express their own views on the content without fear of intimidation from either lecturer or their peers. Lecturers can use whole class discussion to prepare students to move from traditional method of teaching to facilitation.

However, the introduction of black board in the university has brought in another lens that facilitation can be managed. According to Peters (2001) the use of black board make it possible to combine the digital learning and teaching techniques that were discussed in class and develop more discussion in the digital-learning environment. The use of black board has an advantage of allowing discussion of lessons to continue beyond classroom. In other words students who feel shy to participate in class may ask questions and clarity via black board. When lecturers were asked questions on how they use blackboard to manage facilitation, they mentioned that black board give them opportunity to continue with the facilitation of discussion of the lesson even after the lectures. They mentioned that they use discussion tool on black board to continue to facilitation their lesson and also to accommodate students that they may be shy in their classes.

Participants were also asked about the challenges they experience when managing facilitation and their responses were as follows:

- Students who talk too much in class;

- Students who will not talk in class;

- Discussion that turn into argument;

- Unclear comments;

- Discussion that goes off track;

- Students who attack one another.

Facilitation encourages that student participate more, and be responsible for their learning. However, these may go with a challenge that in some instances some students may be more talkative than others, as a result they deny other a chance to participate. In contrast to that some student are just quite by nature, as a results they may be quite for the rest of the lecture and that disturbs facilitation as a teaching method. It becomes a responsibility of a lecturer to create an environment whereby everyone will feel free to participate. Furthermore, during facilitation discussion can into argument. Therefore, it is also the responsibility of a lecturer to ease such situation and encourage respect among students. It makes things easy to set the ground rules during the beginning of the lesson and make sure that all students abide to them. The kind of comments that a teacher gives during facilitation should be clear in order to keep facilitation going. Unclear comments may result into some confusion on the site of the students and this may delay of their learning through facilitation. A lecturer during facilitation should make sure that the discussion is always on track, and students are discussing exactly what are expected to discuss. The same applies with students whom attack one another; it is the responsibility of a lecturer to instil respect among students and also to understand the purpose of the discussion. There is a need for lecturer to be trained on how to manage large classroom using facilitation as a teaching strategy. Looking at constructivist learning theory, one of the first things a lecturer must do is to accept and acknowledge that learners are different and they do not learn the same way. Using facilitation in this regard, lecturer will therefore assist each student to learn through discussing a problem by giving advice rather than telling them what to do (Peters, 2001). Facilitation is an essential ingredient in teaching/learning, and all faculty members can benefit immensely from improving their skills in this performance area. Facilitation can be used with students to help them grow as learners, with graduate students to help them grow as researchers, with committee members to promote team problem solving, and with professional organizations to create effective mission statements and to accomplish strategic objectives. Facilitation involves a mindset of helping others perform better by creating growth opportunities and by providing coaching that allows others to take 
on more ownership and control of their performance.

\section{Conclusion}

Reflecting on the findings of this study one will realise that the use of facilitation is very important in the institutions of higher learning because it prepares students not to rely on their lecturers and be responsible for their own learning. What is important is for lecturers to understand the background that majority of their students are coming from in order to assist them to move gradually from tradition way of learning to facilitation. Furthermore, lecturers need to plan their facilitation by creating an environment that will be conducive for facilitation and also to set facilitation rules were necessary. Looking at first year students, fresh from the high schools, one has to comfort them by familiarizing them with the way of teaching and learning in the institutions of higher learning. For a lecturer to be succefful during facilitation, they should be flexible, creative and up to date. They should also use different techniques and show students you love them. Moreover, you do not allow your students to drink from a bottle, let them go to the river. You should offer skills that lead to learning and respect each one of your students buy understanding that each one is different and special. Lastly, you should not make fun of your students and learn to listen actively and comprehensively to your students.

\section{Recommendations}

The results of this study revealed that students are unable to cope with facilitation since they are used to teaching approach from their high schools. The study therefore, recommends that lecturers should connect teaching and facilitation by gradually introducing students to facilitation. The study further recommended intensive use of facilitation rather than teaching, because facilitation prepare students to be critical thinkers and responsible for their learning. Kolb, (2006) model of learning style was also recommended so that lecturers may understand how students learn. Kolb's model outline different style that students learn, and the model will assist lecturers to know how to deal with concerned students and this will contribute to the student retention and also to quality teaching in the institution.

\section{References}

Babbie, E. (2007). Teaching and Curriculum Methods in South Africa. Reflective Model 3 (1):223-443

Craig, D. L., \& Zimring, C. (2000). Supporting collaborative design groups as design communities. Design Studies, 21:187-204.

Criticos, C. (2002). Getting Practical. 2nd edition. Oxford University of Press: Cape Town.

Davidson, J.W. (1997). Research design quantitative, qualitative and mixed methods. 2nd edition. Juta: Cape Town.

Du Plooy, F. (1997). Reflection in higher education. 3rd edition. Juta: Cape Town.

Ericsson, K. A., Krampe, R. T., \& Tesch-Romer, C. (1993). The role of deliberate practice in the acquisition of expert performance. Psychological Review, 100, 363-406.

Hmelo, C.E., Holton, D.L., \& Kolodner, J.L. (2000). Designing to learn about complex systems. Journal of the Learning Sciences, 9(3), $247-298$.

Holbrook, J., \& Kolodner, J.L. (2000). Scaffolding the development of an inquiry-based (science) classroom. In B. Fishman \& S. O'Conner-Divelbiss (Eds.), Proceedings, International Conference of the Learning Sciences 2000 (ICLS), (pp. 221-227). Mahwah, NJ:Lawrence Erlbaum Associates.

Jacob, M., Vakalisa, N., \& Gawe, N. (2004) Teaching-Learning Dynamics: A participative approach for OBE. $3^{\text {rd }}$ edition. Heinemann. Cape Town.

Kolb, J.L. (1999). Educational implications of analogy: A view from case-based reasoning. American Psychologist, 52(1), 57-66.

Kothari, S.T. (1997). Understanding reflection and models. 2nd edition. Rox and Sons Publishers: Cape Town.

Leedy, D. (2001). Cognition in design: Viewing the hidden side of the design process. Environment and planning B, planning \& design, 20, 257-271.

Mouton, M., \& Marias, J. (1998). Good practice in science teaching: What research has to say. Buckingham: Open University Press.

Peters, O. (2001). Learning and Teaching in distance education. British Library Cataloguin. Britain

Schank, R. C. (1999). Dynamic memory revisited. New York: Cambridge University Press.

Taylor, B.R. (2008). Participation and reflection in classroom. American Journal of preventative medicine, 26(5):419-455.

Van Der Westhuizen, P. (1999). Evaluation a practical guide for teachers. University of Missouri, Columbia. 
